\title{
Núcleo de pesquisas em educação e diversidade: educação especial em foco
}

\author{
Sirlene Vieira de Souza* \\ Universidade de Pernambuco, Recife, PE/ Universidade Federal de Alagoas, Maceió, AL, Brasil

\section{Márcia Lúcia Nogueira de Lima Barros**} \\ Centro Universitário Tiradentes/ Universidade Federal de Alagoas, Maceió, AL, Brasil
}

\begin{abstract}
Resumo
Este artigo teve como objetivo relatar a produção científica de um grupo de pesquisa em educação especial e inclusiva da Universidade Federal de Alagoas (Ufal). Para isso, foram consultados teses, dissertações e trabalhos stricto sensu já finalizados, além de alguns em andamento. Os procedimentos metodológicos foram a revisão bibliográfica sistemática e a pesquisa documental. As teses foram analisadas a partir de suas dimensões e das abordagens adotadas; as dissertações categorizadas e tabeladas por temática, ano e autoria. Os resultados apontaram que as temáticas se ampliam para o fomento da cultura da educação especial inclusiva no estado de Alagoas, que o gênero predominante ainda é feminino, que as palavras-chave dos trabalhos sintetizam suas áreas de foco e os anos de publicação e vínculo são elementos de aproximação. Todas as teses finalizadas estão vinculadas a uma mesma instituição. Palavras-chave: Needi; Produção Científica; Educação Inclusiva.
\end{abstract}

\section{Abstract}

Nucleus of research in education and diversity: special education in focus

This article aimed to report the scientific production of a research group in special and inclusive education at the Federal University of Alagoas (Ufal). For this, the theses, dissertations and the stricto sensu works already consulted and some in progress were consulted. The methodological procedure adopted was a systematic bibliographic review and documentary research. The theses were analyzed based on their dimensions and adopted approaches; the dissertations categorized and tabulated by theme, year and authorship. The results showed that the themes are broadened to foster the culture of inclusive special education in the state of Alagoas and that the predominant gender is still female; that the keywords of the works summarize their areas of focus, and the years of publication and link are elements of approximation. All completed theses are linked to the same institution.

Keywords: Needi; Scientific Production; Inclusive Education.

\section{Resumen}

Núcleo de investigación en educación y diversidad: educación especial en foco

Este artículo tuvo como objetivo informar la producción científica de un grupo de investigación en educación especial e inclusiva en la Universidad Federal de Alagoas (Ufal). Para eso, las tesis, disertaciones

\footnotetext{
* E-mail: sirlenevieiras@hotmail.com
}

** E-mail: marcia.n.barros@globo.com 
y los trabajos stricto sensu ya consultados y algunos en progreso fueron consultados. El procedimiento metodológico adoptado fue una revisión bibliográfica sistemática e investigación documental. Las tesis fueron analizadas en función de sus dimensiones y enfoques adoptados; las disertaciones clasificadas y tabuladas por tema, año y autoría. Los resultados mostraron que los temas se amplían para fomentar la cultura de la educación especial inclusiva en el estado de Alagoas y que el género predominante sigue siendo el femenino; que las palabras clave de los trabajos resumen sus áreas de enfoque, y los años de publicación y enlace son elementos de aproximación. Todas las tesis completadas están vinculadas a la misma institución.

Palabras clave: Needi; Producción Científica; Educación Inclusiva.

\section{Introdução}

O Núcleo de Estudos em Educação e Diversidade (Needi) se debruça sobre as discussões da educação da pessoa com deficiência $(\mathrm{PcD})$, transtornos globais do desenvolvimento (TGD), altas habilidade e superdotação - público-alvo da educação especial no Brasil. O que implica em uma amplitude de atuação nas diversas subáreas que dialogam com a inclusão educacional desse público, como formação docente, tipos de atendimentos, políticas públicas, prática pedagógica e metodologias de intervenção em contexto de inclusão.

Neste artigo apresentar-se-á um recorte, por meio de exposição da produção científica de um grupo de pesquisa, o qual faz parte de uma das linhas do programa de pós-graduação em Educação da Universidade Federal de Alagoas (Ufal), que surgiu com o intuito de fortalecer e ampliar o conhecimento na área da educação especial em nosso estado. O Needi, ao longo do tempo, tem realizado ações que resultaram em avanços acadêmicos e empíricos para a sociedade alagoana.

O Needi surgiu em 2007, ligado à linha de pesquisa Processos Educativos do Programa de Pós-Graduação em Educação da Ufal (NÚCLEO DE ESTUDOS EM EDUCAÇÃO DE DIVERSIDADE, 20 19). Seu início foi marcado principalmente: pelo pioneirismo da discussão em relação ao ensino e aprendizagem na área da Educação Especial/Inclusiva; das atividades de extensão na área (atrelado ao Grupo de Estudos em Atividade Motora Adaptada - Geeama, também coordenado pela $\operatorname{Prof}^{a}{ }^{2}{ }^{a}$ Neiza de Lourdes Frederico Fumes); pela diversidade de seus membros, advindos de cursos como pedagogia, psicologia, educação física, filosofia e outros, e pela necessidade de ampliar os estudos e pesquisas a partir desses distintos olhares e experiências em relação ao processo da educação inclusiva.

Nesse mesmo período, apenas o Needi tecia considerações acerca da educação especial e inclusiva no estado de Alagoas em nível de mestrado, e somente em 2010 
foi iniciado o Doutorado voltado a essa discussão na Ufal. No ano de 2014, criou-se a Linha de Pesquisa Educação e Inclusão de Pessoas com Deficiência ou Sofrimento Psíquico, sendo o Needi um dos grupos de pesquisa vinculado a esta linha que tinha como objetivo desenvolver estudos dos processos educacionais (ensino e aprendizagem) e da inclusão da pessoa com deficiência e/ou em sofrimento psíquico sob diferentes abordagens teóricas, com ênfase em metodologias de intervenção, formação de professores para atuarem no contexto da Educação Inclusiva, como em ambientes não escolares (UNIVERSIDADE FEDERAL DE ALAGOAS, 2019)ํ․

Desde sua origem, o Needi é coordenado pela Prof ${ }^{a}$ Dr $^{a}$ Neiza Fumes, personalidade de referência em Alagoas e no Brasil na discussão dos processos educativos voltados para o público-alvo da educação especial. Assim, esse estudo objetivou relatar a produção científica de um grupo de pesquisa voltado para a educação especial e inclusiva da Ufal. Foi conduzido pela questão: quais as contribuições de um grupo de pesquisa da Ufal para o cenário da educação especial no estado?

\section{Ações desenvolvidas: entrelaçando teoria e prática}

O Needi realizou várias atividades explicitando a indissociabilidade das dimensões acadêmicas, sendo elas: ensino, pesquisa e extensão enquanto balizador de suas ações e seu envolvimento na área da Educação Inclusiva no estado de Alagoas. Além das produções escritas, seminários e reuniões semanais, o Núcleo organizava sistematicamente eventos acadêmicos de referência e relevância no Estado, atraindo participantes de diferentes localidades do país. Dentre estes, três atividades que se tornaram norteadoras dos estudos do Núcleo:

\section{1- Encontro Alagoano de Educação Inclusiva e Encontro Nordestino de Inclusão} no Ensino Superior - Esse evento surgiu como marco para a apresentação do Núcleo à comunidade acadêmica e à sociedade, trazendo em seus títulos a representação do momento vivenciado pela Educação Especial no Brasil e em Alagoas, na perspectiva de construir e ampliar os conhecimentos da área nos diversos contextos sociais. Chegamos à execução de sete encontros (2007, 2008, 2009, 2010, 2013, 2015, 2017), todos com representantes do Ministério da Educação (MEC), mesas redondas com professores renomados nacionalmente, realização de oficinas e apresentações de trabalhos científicos.

\footnotetext{
${ }^{1}$ Programa de Pós-Graduação em Educação, 2019.
} 
Desde o início, os Encontros dialogaram com as mais diversas situações de inclusão escolar, tendo como norteadores as temáticas: políticas públicas, formação docente e acessibilidade na perspectiva de discutir e refletir as questões educacionais referentes ao acesso e permanência com qualidade dos estudantes público-alvo da Educação Especial.

Os cenários apresentados pelos Encontros fortaleceram, valorizaram e disseminaram o respeito às diferenças, além de promover a conscientização da necessidade de um trabalho colaborativo forte, para que de fato a inclusão fosse efetivada em todos os contextos educacionais.

2- Compartilhando Saberes e Práticas sobre a Educação Inclusiva I (2009) e Compartilhando Saberes e Práticas sobre a Educação Inclusiva II (2012) - Vários estudos desenvolvidos no Needi revelaram a necessidade de atividades de formação na área da educação inclusiva para os professores da rede regular de ensino da capital e interior do estado de Alagoas, sendo essa formação mais constante e próxima de sua realidade, sem um caráter linear e meramente cumulativo, mas no sentido de partilhar conhecimentos e experiências singulares em defesa da inclusão escolar. Assim, foi elaborado o Projeto de Extensão Compartilhando Saberes I e II, com o intuito de promover a interação entre pesquisadores, professores e graduandos que atuavam ou tinham interesse na área da educação inclusiva, em que trariam suas vivências, inquietações e ações práticas para discussão à luz dos conhecimentos acadêmicos.

As atividades aconteceram, respectivamente, durante dois meses, sempre aos sábados, no período da manhã e da tarde. Os temas discutidos eram direcionados a: ensino e aprendizagem na perspectiva da educação inclusiva; tecnologias assistivas de pequeno e grande porte; ensino colaborativo na educação inclusiva; introdução a libras e educação de surdos; avaliação na educação inclusiva, jogos e brincadeiras na prática inclusiva. A responsabilidade de nortear as ações era realizada pelos professores mestrandos, mestres e doutores que faziam parte do Núcleo. Importante destacar que, durante o Compartilhando Saberes e Práticas sobre a Educação Inclusiva II (2012), o Núcleo fazia parte do Observatório Nacional de Educação Especial (Oneesp) que era uma rede nacional de pesquisadores que conduzia estudos sobre políticas e práticas acerca da inclusão escolar em todo o território nacional.

3- Sextas Inclusivas (2013, 2014, 2016) - Esse Projeto de Extensão passou a existir como forma de manter uma relação mais próxima entre a Universidade 
e a comunidade, com o interesse de provocar e ampliar discussões relacionadas à educação inclusiva. Assim, o Núcleo mais uma vez percebeu a necessidade de articular ações que promovessem o engajamento de professores da educação básica e superior, graduandos e profissionais de diversas áreas do conhecimento que atuavam junto a pessoa com deficiência com a finalidade de incentivar práticas que excluíssem as barreiras pedagógicas e de comunicação, principalmente, dirimir as barreiras atitudinais garantindo o direito à educação para todos. Para Mercado et al. (2014): "O projeto Sextas Inclusivas promoveu a aproximação entre universidade e os profissionais de educação que trabalhavam com pessoas com deficiência, na perspectiva de conhecer e traçar ações de melhoria da realidade educacional vivenciada” (p. O2).

Desta forma, o Projeto de Extensão Sextas Inclusivas ocorreu durante três anos, com encontros mensais, sempre nas primeiras sextas-feiras de cada mês, contabilizando 10 encontros por ano. Era norteado por temáticas diferenciadas, definidas coletivamente com o grupo de participantes, fortalecendo a perspectiva colaborativa que era o ponto chave das ações do projeto.

Interessante salientar que, como culminância do Sextas Inclusivas I, em novembro de 2013, houve a realização de uma Sessão Pública na Assembleia Legislativa de Alagoas, em parceria com o Núcleo de Estudos em Educação e Diversidade da Ufal, intitulada "A inclusão educacional da pessoa com deficiência e transtornos globais do desenvolvimento no Estado de Alagoas e os serviços de apoio especializado na rede pública”. Estiveram presentes representantes dos Institutos de Ensino Superior do Estado de Alagoas, das Secretarias de Educação Estadual e Municipal, do Ministério Público Estadual, das Instituições de Pessoas com Deficiência, além de políticos, professores, acadêmicos e diversos profissionais que atuam na área. Nesta Sessão Pública foi lido e entregue um documento com algumas reivindicações elaboradas coletivamente durante as Sextas Inclusivas, com a chancela da Ufal.

O Projeto Sextas Inclusivas possibilitou inúmeros debates que permearam as questões das políticas públicas, acessibilidade e formação docente, provocando nos professores, acadêmicos e demais profissionais reflexões que contribuíram sobremaneira para a inclusão da pessoa com deficiência nos diversos contextos sociais de nosso estado. Colocou-se mais uma vez a Universidade enquanto espaço de discussão legítimo. 
Formação de professores e o Método Peripatético: diálogos entre Francisco Imbernón e Antonio Lancetti Vantoir Roberto Brancher, Josete Bittencourt Cardoso e Paula Hosana Silveira Biazus

\section{Abordagem metodológica para o resgate da historicidade do Needi}

Este texto é resultado de um momento de estudos e discussão epistemológica no programa de pós-graduação em educação da Ufal. Para sua construção, foram necessárias algumas decisões, no sentido de delimitar a temática abordada. Assim, optou-se por considerar apenas a produção stricto sensu produzidas pelos integrantes do grupo nos anos de 2007 a 2019. Todos os trabalhos foram orientados pela Coordenadora do grupo de pesquisa.

O estudo caracteriza-se como pesquisa documental, pois faz uma análise de documentos de segunda mão, ou seja, que já foram avaliados, assim como por envolver a seleção de material imprescindível para a consecução dos interesses da pesquisa (LUSTOSA, 2018).

Com o recorte definido, buscou-se acesso aos trabalhos em três fontes: (1) Plataforma Lattes; (2) solicitando diretamente aos autores suas versões e (3) sítio do programa onde a maioria dos trabalhos estão hospedados. Desta maneira, configura-se o trabalho como qualitativo. A análise foi do tipo documental, “[ ...] o uso de documentos para a pesquisa traz uma riqueza de informações, já que elas podem ser utilizadas em várias áreas de ciências humanas e sociais, aproximando o entendimento do objeto na sua contextualização histórica e sociocultural” (CECHINEL et al., 2016, p. 45). Sobre o tipo, recorremos à definição de Gil (2008, p. 4). Os documentos podem ser dos mais variados tipos, escritos ou não, os quais incluem diários, documentos de entidades públicas e privadas, gravações, correspondências, fotografias, filmes, mapas etc. Por terem as teses passado por edição, tratamento de seus autores, revisores e bibliotecários, a pesquisa é bibliográfica com análise de tipo documental (CRESWELL, 2007). Assim, a "análise documental inicia-se pela avaliação preliminar de cada documento, realizando o exame e a crítica do mesmo, sob o olhar, dos seguintes elementos: contexto, autores, interesses, confiabilidade, natureza do texto e conceitos-chave” (CECHINEL et al., 2016, p. 56).

Após a localização e o arquivamento dos trabalhos, como critério de inclusão considerou-se dissertações e teses apenas. Realizada essa primeira etapa, seguiu-se a identificação das temáticas, palavras-chave, autores, ano de defesa e instituição de vínculo das publicações (teses defendidas). Há no texto um detalhamento das teses defendidas e um panorama quantitativo das dissertações concluídas. São citados também os trabalhos dessa natureza que estavam em andamento no período de escrita deste artigo, no entanto, apenas as teses defendidas apresentam uma análise mais detalhada. 
Formação de professores e o Método Peripatético: diálogos entre Francisco Imbernón e Antonio Lancetti Vantoir Roberto Brancher, Josete Bittencourt Cardoso e Paula Hosana Silveira Biazus

\section{Levantamento das teses e dissertações: Um percurso entre os anos de 2007 a 2019}

Atualmente, de acordo com as buscas realizadas na Plataforma Lattes no Conselho Nacional de Desenvolvimento Científico e Tecnológico (CNPq) e na base de dados do programa de pós-graduação em Educação da Ufal, há o registro de 19 dissertações defendidas e duas em andamento, as teses concluídas somam quatro mais seis em andamento. Apresentaremos uma visão geral das 19 dissertações defendidas, assim como as que estão em andamento (Quadro 2), organizadas nas categorias: título; autor; temática; ano de defesa e instituição na qual estão vinculados os trabalhos. O Quadro sintetiza as informações em ordem decrescente por ano de defesa. As teses também estão tabeladas, sejam elas concluídas ou em andamento, todavia, para as análises neste artigo, apenas as teses concluídas foram consultadas na íntegra (Quadro 1).

Quadro 1. Dissertações defendidas pelo Needi.

\begin{tabular}{|c|c|c|c|c|}
\hline Título & Autor & Temática & $\begin{array}{l}\text { Ano de } \\
\text { defesa }\end{array}$ & Instituição de vínculo \\
\hline $\begin{array}{l}\text { A inclusão digital de } \\
\text { professores nas escolas } \\
\text { públicas estaduais de Maceió }\end{array}$ & $\begin{array}{l}\text { Aristóteles da } \\
\text { Silva Oliveira }\end{array}$ & $\begin{array}{l}\text { Inclusão } \\
\text { digital }\end{array}$ & 2007 & $\begin{array}{c}\text { Universidade Federal } \\
\text { de Alagoas/Mestrado } \\
\text { em Educação }\end{array}$ \\
\hline $\begin{array}{l}\text { Formação e Inclusão: } \\
\text { história de vida de } \\
\text { professores de escolas } \\
\text { municipais de Maceió }\end{array}$ & $\begin{array}{l}\text { Márcia Lúcia } \\
\text { Nogueira de } \\
\text { Lima Barros }\end{array}$ & $\begin{array}{l}\text { Formação } \\
\text { docente }\end{array}$ & 2008 & $\begin{array}{c}\text { Universidade Federal } \\
\text { de Alagoas/Mestrado } \\
\text { em Educação }\end{array}$ \\
\hline $\begin{array}{l}\text { Estilo de vida dos alunos com } \\
\text { surdez de uma escola do } 2^{\circ} \text { e } \\
3^{\circ} \text { ciclo da cidade do Porto }\end{array}$ & $\begin{array}{c}\text { Mariana do } \\
\text { Carvalhal } \\
\text { Oliveira Tente }\end{array}$ & $\begin{array}{c}\text { Estilo de vida e } \\
\text { surdez }\end{array}$ & 2009 & $\begin{array}{c}\text { Instituto Universitário } \\
\text { da Maia/Mestrado em } \\
\text { ciências da Educação } \\
\text { física e do desporto }\end{array}$ \\
\hline $\begin{array}{l}\text { Interações sociais entre } \\
\text { surdos e ouvintes no } \\
\text { contexto escolar: os autores } \\
\text { e os seus atos }\end{array}$ & $\begin{array}{l}\text { Janaina Lucena } \\
\text { Santos de Lima }\end{array}$ & $\begin{array}{c}\text { Interações } \\
\text { sociais }\end{array}$ & 2009 & $\begin{array}{c}\text { Universidade Federal } \\
\text { de Alagoas/Mestrado } \\
\text { em Educação }\end{array}$ \\
\hline $\begin{array}{l}\text { O software HagaQue: uma } \\
\text { proposta para a prática da } \\
\text { língua portuguesa escrita da } \\
\text { pessoa surda }\end{array}$ & $\begin{array}{l}\text { Jorge Luiz } \\
\text { Fireman } \\
\text { Nogueira }\end{array}$ & $\begin{array}{c}\text { Ensino } \\
\text { de língua } \\
\text { portuguesa e } \\
\text { surdez } \\
\end{array}$ & 2009 & $\begin{array}{c}\text { Universidade Federal } \\
\text { de Alagoas/Mestrado } \\
\text { em Educação }\end{array}$ \\
\hline $\begin{array}{l}\text { A prática de docentes de } \\
\text { alunos com síndrome de } \\
\text { Down em salas regulares }\end{array}$ & $\begin{array}{c}\text { Arlete } \\
\text { Rodrigues dos } \\
\text { Santos } \\
\end{array}$ & $\begin{array}{l}\text { Prática } \\
\text { Docente }\end{array}$ & 2010 & $\begin{array}{c}\text { Universidade Federal } \\
\text { de Alagoas/Mestrado } \\
\text { em Educação }\end{array}$ \\
\hline
\end{tabular}

Continua 
Continuação

\begin{tabular}{|c|c|c|c|c|}
\hline $\begin{array}{l}\text { A inclusão de uma aluna } \\
\text { com deficiência visual na } \\
\text { Universidade Estadual de } \\
\text { Alagoas: um estudo de caso }\end{array}$ & $\begin{array}{c}\text { Elizete Santos } \\
\text { Balbino }\end{array}$ & $\begin{array}{l}\text { Inclusão e } \\
\text { cegueira }\end{array}$ & 2010 & $\begin{array}{c}\text { Universidade Federal } \\
\text { de Alagoas/Mestrado } \\
\text { em Educação }\end{array}$ \\
\hline $\begin{array}{l}\text { A formação continuada de } \\
\text { professores na perspectiva } \\
\text { da Educação Inclusiva no } \\
\text { município de Maceió }\end{array}$ & $\begin{array}{l}\text { Jaqueline Leite } \\
\text { Vaz de Barros }\end{array}$ & $\begin{array}{l}\text { Formação } \\
\text { continuada }\end{array}$ & 2010 & $\begin{array}{c}\text { Universidade Federal } \\
\text { de Alagoas/Mestrado } \\
\text { em Educação }\end{array}$ \\
\hline $\begin{array}{l}\text { Educação Inclusiva e } \\
\text { formação continuada de } \\
\text { professores mediada pela } \\
\text { EAD: a experiência da UFAL }\end{array}$ & $\begin{array}{c}\text { Tarciana } \\
\text { Angélica Lopes } \\
\text { Silva }\end{array}$ & $\begin{array}{l}\text { Formação } \\
\text { continuada }\end{array}$ & 2010 & $\begin{array}{c}\text { Universidade Federal } \\
\text { de Alagoas/Mestrado } \\
\text { em Educação }\end{array}$ \\
\hline $\begin{array}{l}\text { A inclusão do aluno com } \\
\text { deficiência em Instituições } \\
\text { de Ensino Superior da } \\
\text { cidade de Maceió }\end{array}$ & $\begin{array}{c}\text { Marcia Rafaella } \\
\text { Gracialiano dos } \\
\text { Santos Viana }\end{array}$ & $\begin{array}{c}\text { Inclusão no } \\
\text { ensino superior }\end{array}$ & 2010 & $\begin{array}{c}\text { Universidade Federal } \\
\text { de Alagoas/Mestrado } \\
\text { em Educação }\end{array}$ \\
\hline $\begin{array}{l}\text { Consultoria Colaborativa: } \\
\text { possibilidades e limites para } \\
\text { a prática pedagógica do } \\
\text { professor da sala regular } \\
\text { com alunos surdos } \\
\end{array}$ & $\begin{array}{c}\text { Sirlene Vieira } \\
\text { de Sousa }\end{array}$ & $\begin{array}{l}\text { Consultoria } \\
\text { Colaborativa }\end{array}$ & 2011 & $\begin{array}{c}\text { Universidade Federal } \\
\text { de Alagoas/Mestrado } \\
\text { em Educação }\end{array}$ \\
\hline $\begin{array}{l}\text { Núcleo de atendimento aos } \\
\text { alunos com necessidades } \\
\text { educacionais especiais } \\
\text { (Napne): ações para a } \\
\text { inclusão em uma instituição } \\
\text { de ensino profissional do } \\
\text { estado de Pernambuco }\end{array}$ & $\begin{array}{l}\text { Gerline Maciel } \\
\text { Almeida da } \\
\text { Costa }\end{array}$ & Inclusão & 2011 & $\begin{array}{c}\text { Universidade Federal } \\
\text { de Alagoas/Mestrado } \\
\text { em Educação }\end{array}$ \\
\hline $\begin{array}{l}\text { A prática pedagógica de } \\
\text { professores de instituições } \\
\text { de ensino superior na } \\
\text { cidade de Maceió diante do } \\
\text { processo de inclusão }\end{array}$ & $\begin{array}{c}\text { Soraya Dayana } \\
\text { Guimarães } \\
\text { Santos }\end{array}$ & $\begin{array}{c}\text { Prática } \\
\text { pedagógica e } \\
\text { inclusão }\end{array}$ & 2011 & $\begin{array}{c}\text { Universidade Federal } \\
\text { de Alagoas/Mestrado } \\
\text { em Educação }\end{array}$ \\
\hline $\begin{array}{l}\text { Práticas e diálogos de } \\
\text { uma parceria colaborativa } \\
\text { para a escolarização de um } \\
\text { aluno surdo em uma escola } \\
\text { pública do município de } \\
\text { Craíbas/Alagoas }\end{array}$ & $\begin{array}{c}\text { Viviane Nunes } \\
\text { Sarmento }\end{array}$ & $\begin{array}{c}\text { Parceria } \\
\text { colaborativa }\end{array}$ & 2013 & $\begin{array}{c}\text { Universidade Federal } \\
\text { de Alagoas/Mestrado } \\
\text { em Educação }\end{array}$ \\
\hline
\end{tabular}

Continua 
Continuação

\begin{tabular}{|c|c|c|c|c|}
\hline $\begin{array}{l}\text { Atividade docente e } \\
\text { inclusão: as mediações } \\
\text { produzidas pela Consultoria } \\
\text { Colaborativa }\end{array}$ & $\begin{array}{c}\text { Alessandra } \\
\text { Bonorandi } \\
\text { Dounis }\end{array}$ & $\begin{array}{c}\text { Atividade } \\
\text { docente e } \\
\text { colaboração }\end{array}$ & 2013 & $\begin{array}{c}\text { Universidade Federal } \\
\text { de Alagoas/Mestrado } \\
\text { em Educação }\end{array}$ \\
\hline $\begin{array}{l}\text { A Consultoria colaborativa } \\
\text { como estratégia na formação } \\
\text { continuada de professores } \\
\text { sobre o AEE à pessoa com } \\
\text { surdocegueira }\end{array}$ & $\begin{array}{l}\text { Nágib José } \\
\text { Mendes dos } \\
\text { Santos }\end{array}$ & $\begin{array}{l}\text { Formação } \\
\text { continuada }\end{array}$ & 2014 & $\begin{array}{c}\text { Universidade Federal } \\
\text { de Alagoas/Mestrado } \\
\text { em Educação }\end{array}$ \\
\hline $\begin{array}{l}\text { Atividade docente em sala de } \\
\text { recursos multifuncionais para } \\
\text { educandos com Transtorno } \\
\text { do Espectro Autista. }\end{array}$ & $\begin{array}{c}\text { Marily Oliveira } \\
\text { Barbosa }\end{array}$ & $\begin{array}{l}\text { Atividade } \\
\text { docente e } \\
\text { autismo }\end{array}$ & 2014 & $\begin{array}{c}\text { Universidade Federal } \\
\text { de Alagoas/Mestrado } \\
\text { em Educação }\end{array}$ \\
\hline $\begin{array}{l}\text { Inclusão e aprendizagem } \\
\text { do aluno com deficiência } \\
\text { Intelectual: a Importância } \\
\text { das Habilidades Motoras no } \\
\text { Atendimento Educacional } \\
\text { Especializado - AEE }\end{array}$ & $\begin{array}{c}\text { Francy Kelle } \\
\text { Rodrigues }\end{array}$ & $\begin{array}{l}\text { Atendimento } \\
\text { educacional } \\
\text { especializado }\end{array}$ & 2014 & $\begin{array}{l}\text { Universidade Federal } \\
\text { de Alagoas/Mestrado } \\
\text { em Educação }\end{array}$ \\
\hline $\begin{array}{l}\text { Possibilidades, diálogos e } \\
\text { estratégias para a permanência } \\
\text { do aluno com deficiência na } \\
\text { educação superior }\end{array}$ & $\begin{array}{l}\text { Claudeson } \\
\text { Vilela de } \\
\text { Oliveira }\end{array}$ & $\begin{array}{l}\text { Educação } \\
\text { superior e } \\
\text { deficiência }\end{array}$ & 2017 & $\begin{array}{l}\text { Universidade Federal } \\
\text { de Alagoas/Mestrado } \\
\text { em Educação }\end{array}$ \\
\hline
\end{tabular}

Fonte: Elaborado pelas autoras com base em Souza (2011).

Analisando as dissertações anteriores, percebemos uma amplitude nas temáticas abordadas: quatro se debruçam em torno da formação docente para a inclusão, três são a respeito da prática pedagógica, cinco a respeito trabalhos sobre a inclusão nos diversos espaços educativos, uma dissertação acerca da inclusão digital, uma sobre o estilo de vida de sujeitos surdos, três têm ênfase na pesquisa colaborativa e duas têm foco na educação de surdos. No item instituições, apenas um trabalho não está vinculado à Ufal, a dissertação "Estilo de vida dos alunos com surdez de uma escola do $2^{\circ}$ e $3^{\circ}$ ciclo da cidade do Porto”, ligada ao Instituto Universitário da Maia/Mestrado em ciências da Educação física e do desporto. As produções na área da educação inclusiva são impulsionadas no país após 2008 com a publicação da Política Nacional de Educação Especial na perspectiva da educação Inclusiva (Pnee- 
pei), um crescente empenho para viabilizar as condições ideais de implementação da educação inclusiva no Brasil.

A Política Nacional de Educação Especial na Perspectiva da Educação Inclusiva tem como objetivo o acesso, a participação e a aprendizagem dos alunos com deficiência, transtornos globais do desenvolvimento e altas habilidades/superdotação nas escolas regulares, orientando os sistemas de ensino para promover respostas às necessidades educacionais especiais, garantindo: Transversalidade da educação especial desde a educação infantil até a educação superior; Atendimento educacional especializado; Continuidade da escolarização nos níveis mais elevados do ensino; Formação de professores para o atendimento educacional especializado e demais profissionais da educação para a inclusão escolar; Participação da família e da comunidade; Acessibilidade urbanística, arquitetônica, nos mobiliários e equipamentos, nos transportes, na comunicação e informação; e Articulação intersetorial na implementação das políticas públicas (BRASIL, 2007).

Dentre os vários objetivos, a formação de professores se destaca na política e ecoa nos programas de Pós-Graduação em Educação. Notadamente o Needi é um grupo que dá ênfase às pesquisas que resultam em formação continuada para os docentes ou investigação das diferentes possibilidades de formação ofertadas aos professores da rede de ensino em todos os níveis e etapas pelo poder público. Mesmo com a multiplicidade de temáticas abordadas nas dissertações, há uma convergência teórica e metodológica intrínsecas nos estudos. Observamos, durante as leituras do material coletado, que o Núcleo se orienta a partir da educação numa perspectiva histórica, cultural e de defesa dos direitos em que todos e todas devam aprender juntos na escola comum, valorização das diferenças e da diversidade dentro e fora da sala de aula. Para Matos e Mendes (2014, p. 37),

Discutir sobre as condições necessárias para se garantir o direito à educação da população atendida pela educação especial no país, hoje, significa refletir acerca da proposta de inclusão escolar desses alunos, mais especificamente sobre a política que induz à sua escolarização nas classes comuns das escolas regulares e sobre a realidade da atual política nacional de educação especial na perspectiva inclusiva.

Todos os trabalhos publicizados pelo Needi defendem uma educação pautada na inclusão educacional e social do público-alvo da educação especial em espaços formais de educação e a formação docente para a promoção da educação especial numa perspectiva inclusiva, sempre em consonância com as políticas vigentes de educação e problematizando sua aplicabilidade e estruturação das propostas voltadas para o público-alvo dessa modalidade de educação (Quadro 2). 
Formação de professores e o Método Peripatético: diálogos entre Francisco Imbernón e Antonio Lancetti Vantoir Roberto Brancher, Josete Bittencourt Cardoso e Paula Hosana Silveira Biazus

Quadro 2. Dissertações em andamento no ano de 2019 do Needi.

\begin{tabular}{|l|c|c|c|}
\hline Título & Autor & Temática & Instituição de vínculo \\
\hline $\begin{array}{l}\text { A dimensão subjetiva } \\
\text { da docência: sentidos e } \\
\text { significados de professores } \\
\text { universitários surdos }\end{array}$ & Luana Luiza da & $\begin{array}{c}\text { Dimensão } \\
\text { subjetiva e } \\
\text { Silva }\end{array}$ & $\begin{array}{c}\text { Universidade Federal de } \\
\text { Alagoas/ Mestrado em } \\
\text { Educação }\end{array}$ \\
\hline $\begin{array}{l}\text { A cidade de Garanhuns-PE } \\
\text { nas aulas de Geografia para } \\
\text { alunos surdos: uma parceria } \\
\text { colaborativa com professor do } \\
\text { ensino fundamental }\end{array}$ & $\begin{array}{c}\text { Maria Vitória } \\
\text { de Freitas } \\
\text { Pereira }\end{array}$ & $\begin{array}{c}\text { Ensino de } \\
\text { geografia e } \\
\text { surdez }\end{array}$ & $\begin{array}{c}\text { Anício do estudo: 2018 } \\
\text { Alagoas/ Mestrado em } \\
\text { Educação }\end{array}$ \\
\hline
\end{tabular}

Fonte: Elaborado pelas autoras com base em Souza (2011).

Nos trabalhos em andamento - dissertação e teses -, aparece mais fortemente a discussão da psicologia sócio-histórica, aprofundamento teórico que, mais recentemente, o grupo tem adotado explicitamente em seus trabalhos. A psicologia sócio-histórica tornou-se objeto de estudo essencial para todos os integrantes que estão com as pesquisas em andamento. Para Kahhale e Rosa (2009, p. 25): “Trata-se da concepção materialista histórica dialética. Isso quer dizer que a forma de análise adotada entende o processo histórico humano a partir das determinações fundamentais da base material sobre a superestrutura, num processo necessariamente dialético".

A psicologia sócio-histórica reelabora a concepção de mundo, de homem e de conhecimento para a construção de um saber crítico, isso articulado com as discussões específicas da educação numa perspectiva inclusiva, elemento balizador para os estudos do Needi. O foco das pesquisas diferencia-se, abordando aspectos educacionais, sociais, políticos e teóricos relacionados ao tema da educação da pessoa com deficiência, transtorno global do desenvolvimento, altas habilidades e superdotação, propondo avanços também no campo das práticas com estudantes público-alvo amparados pelos dispositivos legais.

Consoante aos avanços nas produções da área da educação especial e inclusiva (WUO, IVANOVICH, 2016), realizaram um levantamento do quantitativo de produções entre os anos de 2002 a 2015, considerando a influência dos documentos legais pró-inclusão do final da década de 1990. O Gráfico foi construído a partir desse levantamento e ilustra a distribuição dos artigos ao longo dos anos. 
Gráfico. Publicações em Educação Especial.

Publicações em Educação Especial (2002-2015)

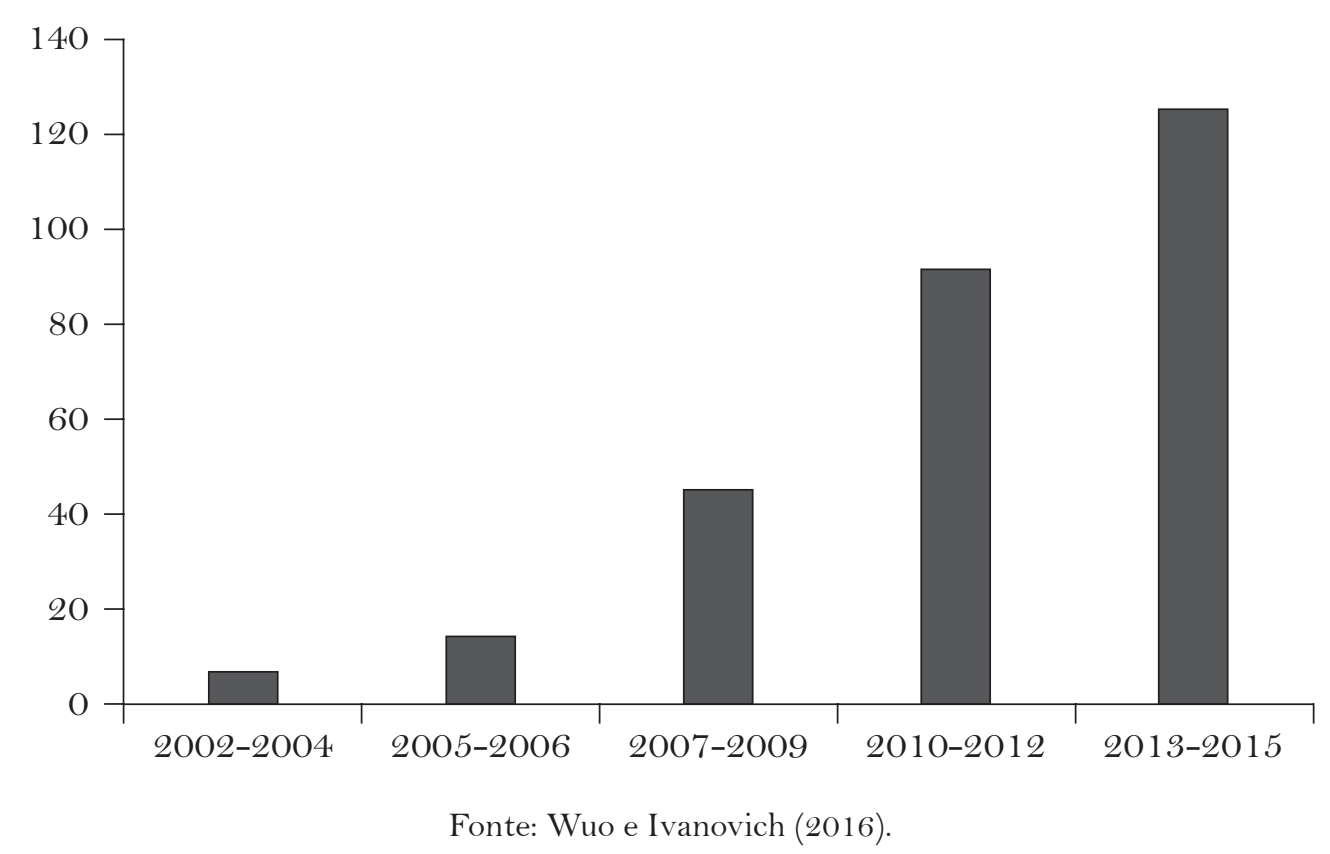

Nota-se que o crescimento das pesquisas acompanha o desenvolvimento de políticas públicas em educação e os desafios teóricos, políticos e pedagógicos vivenciados socialmente (WUO, IVANOVICH, 2016). O Gráfico representa "Uma busca por artigos indexados no Portal de Periódicos da Capes e publicados em português em periódicos com revisão por pares, entre os anos de 2002 e 2015, a partir do descritor "educação especial, apresentou um total de 282 artigos (FUNDAÇÃO COORDENAÇÃO DE APERFEIÇOAMENTO DE PESSOAL DE NÍVEL SUPERIOR, 2019). Destes, 216 foram publicados entre 2010 e 2015 ” (WUO, IVANOVICH, 2016, p. 30).

Nesse levantamento realizado pelos autores, percebemos o aumento das produções a partir dos anos 2000 , quando retomamos as análises das produções do Needi. Sendo este vinculado ao Programa de Pós-Graduação em Educação, observamos a contribuição do grupo para os avanços na educação especial e inclusiva sobretudo na Região Nordeste. A qualidade dos trabalhos reafirma o compromisso com a produção de conhecimento e epistemologia da área, e, apesar de o volume das teses defendidas ser menor, elas são relevantes para os estudos que se desenvolvem, articulados com as discussões inauguradas pelas monografias stricto sensu. As teses concluídas estão dispostas no Quadro 3. 
Quadro 3. Teses defendidas pelo Needi.

\begin{tabular}{|c|c|c|c|c|c|}
\hline Título & Autor & Temática & Palavras-chave & $\begin{array}{c}\text { Ano } \\
\text { de } \\
\text { defesa }\end{array}$ & $\begin{array}{l}\text { Instituição de } \\
\text { vínculo }\end{array}$ \\
\hline $\begin{array}{l}\text { "Mas agora o processo } \\
\text { será diferente do } \\
\text { nosso começo lá } \\
\text { atrás": A proposta } \\
\text { colaborativa crítica } \\
\text { como possibilidade } \\
\text { de transformação de } \\
\text { ações e significações } \\
\text { para o ensino de } \\
\text { Libras }\end{array}$ & $\begin{array}{l}\text { Viviane } \\
\text { Nunes } \\
\text { Sarmento }\end{array}$ & $\begin{array}{c}\text { Ensino de } \\
\text { Libras e } \\
\text { significações }\end{array}$ & $\begin{array}{c}\text { Pesquisa } \\
\text { Colaborativa } \\
\text { Crítica, Educação } \\
\text { Bilíngue para } \\
\text { Surdos, } \\
\text { Ensino de } \\
\text { Libras, Zona de } \\
\text { Desenvolvimento } \\
\text { Coletiva, Psicologia } \\
\text { Sócio-histórica }\end{array}$ & 2015 & $\begin{array}{c}\text { Universidade } \\
\text { Federal de } \\
\text { Alagoas/ } \\
\text { Mestrado em } \\
\text { Educação }\end{array}$ \\
\hline $\begin{array}{l}\text { Identidades do } \\
\text { professor de educação } \\
\text { especial no contexto } \\
\text { de Maceió- Alagoas }\end{array}$ & $\begin{array}{l}\text { Elisangela } \\
\text { Leal de } \\
\text { Oliveira } \\
\text { Mercado }\end{array}$ & $\begin{array}{l}\text { Identidade } \\
\text { docente }\end{array}$ & $\begin{array}{l}\text { Educação Especial, } \\
\text { Identidade } \\
\text { Docente, } \\
\text { Narrativas Orais, } \\
\text { Formação de } \\
\text { Professores, } \\
\text { Desenvolvimento } \\
\text { Profissional }\end{array}$ & 2016 & $\begin{array}{c}\text { Universidade } \\
\text { Federal de } \\
\text { Alagoas/ } \\
\text { Mestrado em } \\
\text { Educação }\end{array}$ \\
\hline $\begin{array}{l}\text { Docência no } \\
\text { processo de inclusão } \\
\text { do estudante com } \\
\text { deficiência em cursos } \\
\text { de educação física: } \\
\text { análise do contexto } \\
\text { universitário brasileiro } \\
\text { e português }\end{array}$ & $\begin{array}{c}\text { Soraya } \\
\text { Dayanna } \\
\text { Guimarães } \\
\text { Santos }\end{array}$ & $\begin{array}{l}\text { Docência e } \\
\text { inclusão }\end{array}$ & $\begin{array}{l}\text { Docência, Educação } \\
\text { Física, Educação } \\
\text { Superior, Inclusão, } \\
\text { Educação Especial }\end{array}$ & 2016 & $\begin{array}{c}\text { Universidade } \\
\text { Federal de } \\
\text { Alagoas/ } \\
\text { Mestrado em } \\
\text { Educação }\end{array}$ \\
\hline $\begin{array}{l}\text { As vivências de } \\
\text { pessoas adultas com } \\
\text { transtorno do espectro } \\
\text { autista na relação } \\
\text { com a escolaridade e } \\
\text { concepções de mundo }\end{array}$ & $\begin{array}{c}\text { Ivanise } \\
\text { Gomes } \\
\text { de Souza } \\
\text { Bittencourt }\end{array}$ & $\begin{array}{l}\text { Transtorno } \\
\text { do espectro } \\
\text { autista }\end{array}$ & $\begin{array}{c}\text { Transtorno do } \\
\text { Espectro Autista, } \\
\text { Vivências, } \\
\text { Narrativas de } \\
\text { Vida, Inclusão, } \\
\text { Defectologia }\end{array}$ & 2018 & $\begin{array}{c}\text { Universidade } \\
\text { Federal de } \\
\text { Alagoas/ } \\
\text { Mestrado em } \\
\text { Educação }\end{array}$ \\
\hline
\end{tabular}

Fonte: Elaborado pelas autoras com base em Souza (2011).

E, no Quadro 4, dispomos as teses em andamento no ano de 2019. 
Formação de professores e o Método Peripatético: diálogos entre Francisco Imbernón e Antonio Lancetti Vantoir Roberto Brancher, Josete Bittencourt Cardoso e Paula Hosana Silveira Biazus

Quadro 4. Teses em andamento.

\begin{tabular}{|c|c|c|c|}
\hline Título & Autor & Temática & Instituição de vínculo \\
\hline $\begin{array}{l}\text { A consultoria colaborativa na } \\
\text { inclusão de alunos com deficiência } \\
\text { - a atuação do Terapeuta } \\
\text { Ocupacional }\end{array}$ & $\begin{array}{c}\text { Alessandra } \\
\text { Bonorandi } \\
\text { Dounis }\end{array}$ & $\begin{array}{l}\text { Consultoria } \\
\text { colaborativa e } \\
\text { inclusão }\end{array}$ & $\begin{array}{l}\text { Universidade Federal de } \\
\text { Alagoas/Mestrado em } \\
\qquad \text { Educação } \\
\text { Início do estudo: } 2015\end{array}$ \\
\hline $\begin{array}{l}\text { Impacto das políticas públicas } \\
\text { educacionais na formação de } \\
\text { professores para a inclusão }\end{array}$ & $\begin{array}{l}\text { Bruno Cleiton } \\
\text { Macedo do } \\
\text { Carmo }\end{array}$ & $\begin{array}{l}\text { Políticas } \\
\text { públicas e } \\
\text { inclusão }\end{array}$ & $\begin{array}{l}\text { Universidade Federal de } \\
\text { Alagoas/Mestrado em } \\
\text { Educação } \\
\text { Início do estudo: } 2016 \\
\end{array}$ \\
\hline $\begin{array}{l}\text { A constituição de uma escola } \\
\text { bilíngue para surdos na rede } \\
\text { pública de Maceió }\end{array}$ & $\begin{array}{c}\text { Sirlene Vieira } \\
\text { de Souza }\end{array}$ & $\begin{array}{c}\text { Escola bilíngue } \\
\text { para surdos }\end{array}$ & $\begin{array}{l}\text { Universidade Federal de } \\
\text { Alagoas/Mestrado em } \\
\text { Educação } \\
\text { Início do estudo: } 2018 \\
\end{array}$ \\
\hline $\begin{array}{l}\text { A pesquisa colaborativa como } \\
\text { mediatizadora da atuação do } \\
\text { professor do Atendimento } \\
\text { Educacional Especializado no } \\
\text { processo educacional do aluno } \\
\text { com surdocegueira: uma leitura } \\
\text { sócio-histórica }\end{array}$ & $\begin{array}{l}\text { Nágib José } \\
\text { Mendes dos } \\
\text { Santos }\end{array}$ & $\begin{array}{l}\text { Surdo-cegueira } \\
\text { e a pesquisa } \\
\text { colaborativa }\end{array}$ & $\begin{array}{l}\text { Universidade Federal de } \\
\text { Alagoas/Mestrado em } \\
\qquad \text { Educação } \\
\text { Início do estudo: } 2019\end{array}$ \\
\hline $\begin{array}{l}\text { Políticas de inclusão escolar para o } \\
\text { aluno com deficiência nas escolas } \\
\text { indígenas de Palmeira dos Índios }\end{array}$ & $\begin{array}{c}\text { Larissa } \\
\text { Ferreira Ferro }\end{array}$ & $\begin{array}{l}\text { Inclusão } \\
\text { em escolas } \\
\text { indígenas }\end{array}$ & $\begin{array}{l}\text { Universidade Federal de } \\
\text { Alagoas/Mestrado em } \\
\text { Educação } \\
\text { Início do estudo: } 2019 \\
\end{array}$ \\
\hline $\begin{array}{l}\text { Os sentidos e Significados de } \\
\text { docentes e discentes universitários } \\
\text { acerca das altas habilidades/ } \\
\text { superdotação e do processo de } \\
\text { inclusão na educação superior: } \\
\text { uma análise a partir da psicologia } \\
\text { sócio-histórica }\end{array}$ & $\begin{array}{c}\text { Raíssa Matos } \\
\text { Ferreira }\end{array}$ & $\begin{array}{l}\text { Superdotação, } \\
\text { altas } \\
\text { habilidades e } \\
\text { a psicologia } \\
\text { sócio-histórica }\end{array}$ & $\begin{array}{l}\text { Universidade Federal de } \\
\text { Alagoas/Mestrado em } \\
\qquad \text { Educação } \\
\text { Início do estudo: } 2019\end{array}$ \\
\hline
\end{tabular}

Fonte: Elaborado pelas autoras com base em Souza (2011).

Compreender as teses publicadas pelo Núcleo é visualizar os caminhos científicos trilhados pelo grupo, as teses concentram e expandem ao mesmo tempo as investigações, produções teóricas, empíricas e epistemológicas na área da educação especial e inclusiva. 
Formação de professores e o Método Peripatético: diálogos entre Francisco Imbernón e Antonio Lancetti Vantoir Roberto Brancher, Josete Bittencourt Cardoso e Paula Hosana Silveira Biazus

\section{A) As temáticas}

$\mathrm{Na}$ consulta ao texto das quatro teses defendidas, conseguimos elencar suas temáticas principais a partir de seus resumos, palavras-chaves e conteúdo geral. São estas: Ensino de Libras e significações; Identidade docente; Docência e inclusão; Transtorno do Espectro Autista. Assim como nas dissertações, as teses apresentam temáticas diversas com objetos específicos, todavia convergem para uma mesma discussão - aspectos educacionais inclusivos do público-alvo da educação especial no Brasil:

A inclusão, em contrapartida, implica em mudança no sistema educacional, na ruptura de base em sua estrutura organizacional, em eliminar o conformismo da rotina escolar dos professores, gestores e familiares. Desse modo, a inclusão é uma saída para que se possa fluir com uma ação formadora para todos. Compreende-se, pela perspectiva da inclusão, que todos os sujeitos são diferentes e que as instituições escolares precisam ser transformadas para atender às pessoas com ou sem deficiência, respeitando as suas diferenças. Nesse processo, a comunidade escolar adere a práticas pedagógicas que desenvolvem as habilidades intelectuais, culturais e sociais dos estudantes (CAIMI, LUZ, 2018, p. 86).

Essa definição de educação inclusiva das autoras se equaliza com a compreensão acerca da temática defendida pelo Núcleo de pesquisa, por isso, os estudos desenvolvidos pelo Needi objetivam fomentar a cultura da inclusão no estado de Alagoas. Para isso, os procedimentos metodológicos adotados nas teses são fundamentalmente de cunho qualitativo interventivo: observações participantes; história oral; autoconfrontação e colaboração crítica, todos os trabalhos são fundamentados na abordagem histórico-cultural e a psicologia sócio-histórica de Vygotsky. Todas as pesquisas do núcleo são de campo e empíricas.

\section{B) Palavras-chave}

Consultando as teses defendidas obtemos as palavras-chave de cada trabalho como dispostas no Quadro 3, constatamos que estas representam coerentemente as subtemáticas foco dos trabalhos, mediante a complexidade e amplitude da área da educação especial. Em tela temos as seguintes palavras-chave:

Ensino de Libras. Zona de Desenvolvimento Coletiva. Psicologia Sócio Histórica. Pesquisa Colaborativa Crítica. Educação Bilíngue para surdos (SARMENTO, 2015); Educação Especial. Identidade docente. Narrativas orais. Formação de professores. Desenvolvimento profissional (MERCADO, 2016); Docência. Educação Física. Educação Superior. Inclusão. Educação Especial (SANTOS, 2016); Transtorno do Espectro Autista, Vivências, Narrativas de vida, Inclusão, Defectologia (BITTENCOURT, 2018). 
Observando os termos, percebe-se a extensão diversificada das pesquisas desenvolvidas pelo grupo, apesar de uma base teórica metodológica uníssona. O núcleo se debruça teoricamente nos estudos da sócio-histórica, cultura, identidade, diversidade, diferenças, inclusão, surdez, Transtorno do Espectro do Autismo (TEA), formação e identidade docente. As tipologias das deficiências investigadas pelos trabalhos que se propõem a tal objetivo foram duas: surdez e autismo; as outras duas teses discutiram formação docente no ensino superior, docência e identidade.

\section{C) Autores}

Quanto ao gênero dos autores das teses defendidas todos são mulheres. Nas em andamento há dois autores masculinos. Nas dissertações apresentadas na seção anterior, das 19 finalizadas, apenas quatro apresentam autor do gênero masculino e, das duas dissertações em andamento, seus autores são do gênero feminino. Fenômeno semelhante foi constatado nas produções dos artigos da revista brasileira de educação especial no ano de 2005 a 2015 ,

No que diz respeito ao gênero dos pesquisadores, foi identificada a participação de 97 autores nos textos em estudo, dos quais 75 são do gênero feminino e 22 são do gênero masculino, o que evidencia uma presença dominante das mulheres na produção acerca do tema da Educação Inclusiva (CAIMI, LUZ, 2018, p. 667).

A prevalência das mulheres na educação especial é uma característica predominante desde o século XX. Socialmente há uma representação da docência como atividade fundamentalmente feminina, o que se intensifica na modalidade da educação especial, uma vez que "a sociedade brasileira associa à função do professor, características geralmente consideradas femininas como a atenção, a delicadeza e a meiguice” (CAIMI, LUZ, 2018, p. 670).

Para além do gênero, realizamos o levantamento da formação inicial dos autores, os resultados são: Pedagogia, Educação física, Enfermagem, Psicologia e Terapia ocupacional. No histórico do Needi, os participantes que compõem o núcleo apresentam as mais variadas áreas de formação inicial, destacando-se em escala: Educação física; Pedagogia; Psicologia; Biologia; História; Filosofia; Enfermagem; Terapia ocupacional e Direito. A predominância é dos cursos de licenciatura, portanto, atividade de destaque na docência.

\section{D) Ano de defesa e Instituição de vínculo das publicações}

Dois trabalhos foram defendidos e publicizados no mesmo ano, 2016, enquanto os demais em 2015 e 2018 . Há um volume considerável de dissertações que datam de 2007 a 2017, já as teses se concentram nos últimos quatro anos. 
Em relação às pesquisas em andamento, é possível que mudem a construção de seus títulos no percurso de conclusão, os títulos tabelados correspondem aos registrados na plataforma do currículo Lattes da orientadora e coordenadora do Needi (CONSELHO NACIONAL DE DESENVOLVIMENTO CIENTÍFICO E TECNOLÓGICO, 2019). Nos 10 anos do grupo, o volume de produções são bastante variados, há uma concentração maior em dissertações, porém, os eventos e publicações em periódicos, artigos em livros também são bastante significativos, em relação as teses. O Programa de Pós-Graduação de Doutorado tem menos de uma década de funcionamento, um dos motivos do número ainda pequeno de teses defendidas, quando somado o total de orientações de teses são 10 ao total, das quais seis estão em andamento, considerando o primeiro semestre do ano de 2019. Os eixos norteadores das pesquisas do grupo são: a educação especial inclusiva, a diversidade e as diferenças. A educação inclusiva requer o envolvimento de todos no sistema educacional, para que as diversidades dos alunos possam ser vistas e vividas de maneira plena e satisfatória, criando condições de responder aos seus desejos e necessidades, como sujeitos autônomos (CAIMI, LUZ, 2018, p. 676-677).

\section{Considerações}

O Needi se destaca no estado de Alagoas, em nível nacional e internacional, com a articulação dos pesquisadores que o compõe com universidades portuguesas e paulistas. O Núcleo há uma década se empenha em contribuir com os avanços da educação inclusiva no estado, assim, este artigo teve como objetivo relatar a produção científica de um grupo de pesquisa em educação Especial e Inclusiva da Ufal. Observamos a vasta produção do grupo, a ampla discussão que perpassa a educação especial na perspectiva da educação inclusiva, políticas inclusivas e formação docente. O desenvolvimento das pesquisas destaca a maturidade teórica e prática das ações resultantes dos projetos que deram origem aos trabalhos realizados pelo grupo de pesquisa, alinhados aos fundamentos da psicologia sócio-histórica. Portanto, a relevância do Núcleo no contexto acadêmico é irrefutável, pois sua contribuição na elaboração e reelaboração de saberes exerceu/exerce influência na práxis docente dentro das escolas aonde as pesquisas foram/são desenvolvidas.

A expectativa é o aumento progressivo do conhecimento acerca da educação especial regionalmente, mais precisamente no Nordeste, no intuito de responder demandas e necessidades locais na promoção de uma educação mais inclusiva. 
Formação de professores e o Método Peripatético: diálogos entre Francisco Imbernón e Antonio Lancetti Vantoir Roberto Brancher, Josete Bittencourt Cardoso e Paula Hosana Silveira Biazus

\section{Referências}

BITTENCOURT, I. As vivências de pessoas adultas com transtorno do espectro autista na relação com a escolaridade e concepções de mundo. 2018. 235 fls. Tese (Doutorado em educação) - Centro de Educação, Universidade Federal de Alagoas, Maceió, AL, 2018.

BRASIL. Ministério da Educação - MEC. Política nacional de educação especial na perspectiva da educação inclusiva. Brasília, DF, 2007.

CAIMI, F. E.; LUZ, R. N. Inclusão no contexto escolar: estado do conhecimento, práticas e proposições. Revista Educação Especial, Santa Maria, v. 31, n. 62, p. 665-82, jul./set. 2018. https://doi.org/10.5902/1984686X29202

CECHINEL, A. et al. Estudo/análise documental: uma revisão teórica e metodológica. Criar Educação, Criciúma, v. 5, n. 1, p. 1-7, jan./jun. 2016. https://doi.org/10.18616/ce.v5i1.2446

CONSELHO NACIONAL DE DESENVOLVIMENTO CIENTÍFICO E TECNOLÓGICO - CNPq. Neiza de Lourdes Frederico Fumes. Currículo Lattes, 2019. Disponível em: <http://lattes.cnpq.br/8834824295660511>. Acesso em: 27 abr. 2019.

CRESWELL, J. W. Projeto de pesquisa: métodos qualitativo, quantitativo e misto. 2. ed. Porto Alegre, RS: Artmed, 2007.

FUNDAÇÃO COORDENAÇÃO DE APERFEIÇOAMENTO DE PESSOAL DE NÍVEL SUPERIOR - CAPES. Catálogo de teses e dissertações. Brasília, DF: Ministério da Educação, 2019. Disponível em: < https://catalogodeteses.capes.gov.br/catalogo-teses/>. Acesso em: 27 abr. 2019.

GIL, A. C. Como elaborar projetos de pesquisa. 4. ed. São Paulo, SP: Atlas, 2008.

KAHHALE, E. M. S. P; ROSA, E. Z. A construção de um saber crítico em psicologia. In: BOCK, A. M. B.; GONÇALVES, M. G. M. A dimensão subjetiva da realidade: uma leitura sócio-histórica. São Paulo, SP: Cortez, 2009. p. 19-53.

LUSTOSA, A. V. M. F. Teses e dissertações em educação especial na região nordeste no período de 1997 a 2012. Revista Educação Especial, Santa Maria, v. 31 n. 60, p. 51-64, jan./mar. 2018. https://doi.org/10.5902/1984686X18997

MATOS, S. N.; MENDES, E. G. A proposta de inclusão escolar no contexto nacional de implementação das políticas educacionais. Práxis Educacional, Vitória da Conquista, v. 10, n. 16, p. 35-59, jan./jun. 2014.

MERCADO, E. Identidades do professor de educação especial no contexto de Maceió, Alagoas. 2016. 320 fls. Tese (Doutorado em Educação) — Centro de Educação, Universidade Federal de Alagoas, Maceió, AL, 2016. 
MERCADO, E. et al. Reflexões da formação docente no projeto de extensão sextas inclusivas da Universidade Federal de Alagoas. In: CONGRESSO BRASILEIRO DE EDUCAÇÃO ESPECIAL, 6. 2014, São Carlos. Anais... Campinas, SP: Galoá, 2014. Disponível em: <https://proceedings.science/cbee/cbee6/papers/reflexoes-da-formacao-docente-no-projeto-de-extensao-sextas-inclusivas-da-universidade-federal-de-alagoas>. Acesso em: 26 jul. 2019.

NÚCLEO DE ESTUDOS EM EDUCAÇÃO DE DIVERSIDADE - NEEDI. Blog do Needi. Maceió, AL: Universidade Federal de Alagoas, 2019. Disponível em: <http:// neediufal.blogspot.com>. Acesso em: 18 abr 2019.

UNIVERSIDADE FEDERAL DE ALAGOAS - UFAL. Histórico. Maceió, AL: Centro de Educação, 2019. Disponível em: <http://www.ufal.edu.br/unidadeacademica/ cedu/pos-graduacao/mestrado-e-doutorado-em-educacao/institucional/historia $>$. Acesso em: 18 abr. 2019.

SANTOS, S. D. Docência no processo de inclusão do estudante com deficiência em cursos de educação física: análise do contexto universitário brasileiro e português. 2016. 290 fls. Tese (Doutorado em educação) — Centro de Educação, Universidade Federal de Alagoas, Maceió, AL, 2016.

SARMENTO, V. Mas agora o processo será diferente do nosso começo lá atrás: a proposta colaborativa crítica como possibilidade de transformação de ações e significações para o ensino de libras. 2018. 270 fls. Tese (Doutorado em educação) — Centro de Educação, Universidade Federal de Alagoas, Maceió, AL, 2018.

SOUZA, S. V. S. Consultoria colaborativa: possibilidades e limites para a prática pedagógica do professor da sala regular com alunos surdos. 2011. 129 fls. Dissertação (Mestrado em educação) - Centro de Educação, Universidade Federal de Alagoas, Maceió, AL, 2011.

WUO, A. S.; IVANOVICH, A. C. F. Educação especial e educação inclusiva: um balanço das revisões de literatura. In: CONGRESSO BRASILEIRO DE EDUCAÇÃO ESPECIAL, 7. 2016, São Carlos. Anais... Campinas, SP: Galoá, 2016. Disponível em: https://proceedings.science/cbee/cbee7/papers/educacao-especial-e-educacao-inclusiva--um-balanco-das-revisoes-de-literatura-. Acesso em: 27 abr. 2019.

Submissão em: 27/09/2019

Aceito em: 20/03/2020 